\title{
Development of an efficient, non-viral transfection method for studying gene function and bone growth in human primary cranial suture mesenchymal cells reveals that the cells respond to BMP2 and BMP3
}

Prem P Dwivedi ${ }^{1,2}$, Peter J Anderson ${ }^{1,2,3+}$ and Barry C Powell ${ }^{1,2^{*}}$

\begin{abstract}
Background: Achieving efficient introduction of plasmid DNA into primary cultures of mammalian cells is a common problem in biomedical research. Human primary cranial suture cells are derived from the connective mesenchymal tissue between the bone forming regions at the edges of the calvarial plates of the skull. Typically they are referred to as suture mesenchymal cells and are a heterogeneous population responsible for driving the rapid skull growth that occurs in utero and postnatally. To better understand the molecular mechanisms involved in skull growth, and in abnormal growth conditions, such as craniosynostosis, caused by premature bony fusion, it is essential to be able to easily introduce genes into primary bone forming cells to study their function.

Results: A comparison of several lipid-based techniques with two electroporation-based techniques demonstrated that the electroporation method known as nucleofection produced the best transfection efficiency. The parameters of nucleofection, including cell number, amount of DNA and nucleofection program, were optimized for transfection efficiency and cell survival. Two different genes and two promoter reporter vectors were used to validate the nucleofection method and the responses of human primary suture mesenchymal cells by fluorescence microscopy, RT-PCR and the dual luciferase assay. Quantification of bone morphogenetic protein (BMP) signalling using luciferase reporters demonstrated robust responses of the cells to both osteogenic BMP2 and to the antiosteogenic BMP3.

Conclusions: A nucleofection protocol has been developed that provides a simple and efficient, non-viral alternative method for in vitro studies of gene and protein function in human skull growth. Human primary suture mesenchymal cells exhibit robust responses to BMP2 and BMP3, and thus nucleofection can be a valuable method for studying the potential competing action of these two bone growth factors in a model system of cranial bone growth.
\end{abstract}

Keywords: Transfection, Nucleofection, Skull, Bone, Primary cell culture, Mesenchymal, BMP2, luciferase

\footnotetext{
* Correspondence: barry.powell@adelaide.edu.au

${ }^{\dagger}$ Equal contributors

'Craniofacial Research Group, Women's and Children's Health Research Institute, 72 King William Road, North Adelaide, South Australia 5006,

Australia

${ }^{2}$ Discipline of Paediatrics, University of Adelaide, North Terrace Adelaide,

South Australia 5006, Australia

Full list of author information is available at the end of the article
} 


\section{Background}

The ability to transfect DNA into mammalian cells is vital in biomedical research, particularly in studies of mechanistic understanding and clinical application. In particular, functional analyses of proteins, their trafficking and localization, gene expression studies, tissue engineering and gene therapy frequently require introduction of plasmid DNA into mammalian cells. Some questions can be addressed using transformed cell lines but they are artificial models harbouring one or more oncogenic mutations that may have had widespread and poorly characterized effects on cellular biology, and reliance on their use alone can distort views of function and significance. In contrast, primary cultured cells are non-transformed and typically comprise a mixed population that is more representative of the cellular complexity of the tissue of origin. However, lipid-based methods commonly used to transfect transformed cells are generally ineffective with primary cells and achieving efficient transfection of primary cells is a common problem in biomedical research. The two major alternatives to lipid-based methods for introducing genes into cells are viral transduction and electroporation. Although viral transduction can be effective, construction and handling of viral vectors and the processes involved in transduction are time consuming and require specialist expertise and, in cases of clinical application, safety issues can become paramount [1-4]. Non-viral electroporation of genes into primary cells can provide a simple and efficient alternative but, typically, primary cells of different origins cannot necessarily be transfected using the same conditions, which then need to be optimized [5-10].

Growth of the skull vault occurs via a different process to that of long bone growth and less is known about the mechanisms involved. Whereas growth of long bones occurs via a two step process (known as endochondral ossification) in which chondrogenesis precedes osteogenesis [11-13], growth of the calvarial plates of the skull vault occurs via direct differentiation of mesenchymal osteoprogenitor cells into bone-forming osteoblasts. This occurs at the fibrous suture located between calvaria and is known as intramembranous ossification [13]. Premature bony fusion of cranial sutures results in craniosynostosis, a developmental disorder that affects one in 2500 live births [14], with dramatic consequences for affected children, including raised intracranial pressure, impaired vision and hearing, intellectual disability and psychological problems associated with different head shapes [15-18]. Human primary calvarial suture mesenchymal cells derived from the bone forming regions between the skull calvarial plates can be used to study the molecular mechanisms involved in skull growth and the premature bony fusion that characterizes craniosynostosis [19-21] in the pursuit of biologically-based, adjunctive therapies to minimize the need for recurrent surgical correction during early childhood development. However, lack of an efficient method for transfection limits progress towards this goal.

In this study we compared lipid-based and electroporation-based techniques to introduce genes into human primary calvarial suture mesenchymal cells and have shown that an optimized electroporation-based nucleofection technique provides the most effective and reliable transfection. We have conducted benchmark experiments to validate gene expression and study function using glypican 3 (Gpc3) a proteoglycan capable of regulating a variety of growth factors [22], and to measure cell responses to two important bone growth factors, bone morphogenetic protein 2 (BMP2) and BMP3, which have antagonistic roles in bone growth [23,24].

\section{Results}

Transfection of human primary calvarial suture mesenchymal cells using the Amaxa Nucleofector- II

Initially, for transfection of human primary calvarial suture mesenchymal cells we tested several lipid-based, commercial transfection agents with a Green Fluorescent Protein (GFP)-containing expression construct, pmaxGFP (Table 1). None of the transfection agents, except endofectine and metafectine, showed any significant cell death as observed by light microscopy but the percentage of GFP-positive cells determined by flow cytometry indicated that these agents produced only 1-4. \% transfection efficiency (Table 1). As a result of these very low transfection efficiencies, we tested electroporationbased methods using the Neon transfection system and the Amaxa Nucleofector II system. Using the Neon transfection system with human primary cranial suture mesenchymal cells, at best we achieved a transfection efficiency of $10 \%$ (data not shown) with recommended amounts of plasmid DNA (500 ng pmaxGFP) and cells $(100,000)$, and recommended optimization protocols that varied pulse voltage (850-1600 V), pulse width (10$40 \mathrm{~ms}$ ) and pulse number (one to three pulses). In contrast, with the Amaxa Cell Line Optimization

Table 1 Analysis of transfection efficiency of human primary calvarial suture mesenchymal cells by lipid-based transfection methods

\begin{tabular}{lll}
\hline Transfection Method & \% Cell Survival & \% Transfection Efficiency \\
\hline Turbofect & ND & $1.5 \pm 0.2$ \\
Lipofectamine 2000 & ND & $1.6 \pm 0.1$ \\
DOTAP & ND & $1.4 \pm 0.1$ \\
X-Fect & ND & $4.1 \pm 0.1$ \\
Endofectine & $64.9 \pm 8.5$ & $2.8 \pm 0.6$ \\
Metafectine & $89.6 \pm 12.1$ & $3.5 \pm 0.3$ \\
\hline
\end{tabular}

$\mathrm{ND}=$ not determined. Values $\pm \mathrm{SD}$ represent the mean of 3 biological replicates. 
Nucleofector Kit transfection efficiencies of 35-56 \% were achieved using program T030 and nucleofector solution-V (35\%) and nucleofector solution-L (56 \%); however, cell survival was variable (Table 2). To optimize transfection efficiencies and cell survival we tested several other nucleofector kits (Basic Nucleofector Kit for Primary Mammalian Epithelial Cells and Cell Line Nucleofector Kit $\mathrm{T}$ for Bone Marrow) which have been used to transfect primary cells from other tissues. We never achieved transfection efficiencies above $10 \%$ using these kits (data not shown). Therefore, we optimized plasmid concentration and cell number using the T030 program and nucleofector solution-L, which had initially produced the highest transfection efficiency in the human primary suture cells. We tested 3, 6 and $9 \mu \mathrm{g}$ of pmaxGFP per transfection and found that increasing amounts of plasmid resulted in lower cell survival (Table 3). However, transfection efficiency was higher with more plasmid and the total number of transfected cells obtained with either 3 or $6 \mu \mathrm{g}$ plasmid was similar. Next, we investigated transfection efficiency and cell survival using increasing cell numbers in the transfection mix (Table 4). Increasing cell numbers resulted in lower cell survival but higher transfection efficiency. The highest relative numbers of living transfected cells were achieved with inputs of $0.5 \times 10^{6}$ and $1 \times 10^{6}$ cells with $3 \mu \mathrm{g}$ of plasmid. Figure 1 shows GFP fluorescence in living, transfected cells.

Validation of the nucleofection method demonstrates cellular responses to BMP2 and BMP3 in human primary calvarial suture mesenchymal cells

To demonstrate expression from other transfected plasmids and test functional responses in the cells, we first nucleofected a Gpc3 expression vector into primary human calvarial suture mesenchymal cells using nucleofection. Expression of the nucleofected Gpc3 was confirmed by RT-
PCR (Figure 2). Next, cell function studies were conducted using the dual luciferase assay to test cell responses to two growth factor responsive luciferase reporter constructs, pID183-Luc and p3TP-Lux, responsive to BMP2 [25] and BMP3 [26] respectively. Twenty-four hrs post-transfection of pID183-Luc, BMP2 was added to transfected cells and luciferase activity of the BMP2 responsive construct was measured 8, 16, 24 or $48 \mathrm{hrs}$ later. Maximal induction (4.5 fold) occurred 24 hrs post BMP2 treatment (Figure 3A). To investigate responses to BMP3, cells were transfected with p3TP-Lux and 24 hrs later BMP3 was added, then luciferase activity was assayed a further 24 hrs later. A dose of $50 \mathrm{ng} / \mathrm{ml}$ of BMP3 produced a 2 fold induction in luciferase activity (Figure 3B).

\section{Discussion}

Inefficient introduction of plasmid DNA into primary cultures of mammalian cells is a common and frustrating problem in biomedical research that can restrict analyses of gene and protein function and limit progress in the understanding of human biology. Human primary cranial suture mesenchymal cells are an heterogeneous cell population derived from the bone forming regions between the calvarial plates of the skull and are responsible for driving the rapid skull growth that occurs in utero and postnatally. There are reports describing gene expression profiles of human cranial sutures in normal development and in abnormal medical conditions such as premature bony suture fusion in craniosynostosis, but limited information about how suture cell functions are regulated and the molecular consequences of genetic mutations on them $[20,27,28]$. This fundamental information can typically be derived by in vitro manipulation of gene and protein expression in cell-based assays, approaches that require efficient, simple and reliable cell transfection methods to enable general implementation. Lipid-based methods used to transfect plasmid DNA into mammalian cell lines are generally not

Table 2 Effect of specific nucleofection programs on cell survival and transfection efficiency of human primary calvarial suture mesenchymal cells

\begin{tabular}{|c|c|c|c|c|c|}
\hline \multirow[b]{2}{*}{ Nucleofection program } & \multirow[b]{2}{*}{$\operatorname{pmaxGFP}(\mu \mathrm{g})$} & \multicolumn{2}{|c|}{ V- Nucleofector buffer } & \multicolumn{2}{|c|}{ L- Nucleofector buffer } \\
\hline & & $\%$ Cell survival & $\%$ Transfection efficiency & $\%$ Cell survival & $\%$ Transfection efficiency \\
\hline No-Program control & $3 \mu \mathrm{g}$ & 99.2 & 0.2 & $98.8 \pm 0.7^{*}$ & $0.4 \pm 0.1^{*}$ \\
\hline T-030 & No GFP control & 26 & 0.3 & $37.0 \pm 7.0^{*}$ & $0.6 \pm 0.2^{*}$ \\
\hline $\mathrm{T}-030$ & $3 \mu \mathrm{g}$ & 14 & 35.5 & $19.0 \pm 2.0^{*}$ & $56.2 \pm 9.1^{*}$ \\
\hline A-020 & $3 \mu \mathrm{g}$ & 20 & 10.4 & 24 & 3.8 \\
\hline T-020 & $3 \mu \mathrm{g}$ & 14 & 22.7 & 17 & 31.6 \\
\hline$x-001$ & $3 \mu \mathrm{g}$ & 24 & 12.8 & 27 & 8.0 \\
\hline$x-005$ & $3 \mu \mathrm{g}$ & 24 & 16.5 & 20 & 13.7 \\
\hline L-029 & $3 \mu \mathrm{g}$ & 11 & 23.5 & 18 & 22.3 \\
\hline D-023 & $3 \mu \mathrm{g}$ & 15 & 27.2 & 20 & 14.8 \\
\hline
\end{tabular}

Values \pm SD with * represent the mean of 2 independent experiments, each with 2 from biological replicates. The other values are derived from one experiment with 2 biological replicates. 
Table 3 Effect of increasing plasmid concentration on cell survival and transfection efficiency using kit- $L$ and the T030 program

\begin{tabular}{llll}
\hline Program & pmaxGFP $(\boldsymbol{\mu g})$ & $\%$ Cell survival & $\%$ Transfection efficiency \\
\hline T-030 & No GFP control & $36.0 \pm 4.2^{*}$ & $0.7 \pm 0.2^{*}$ \\
T-030 & $3 \mu \mathrm{g}$ & $19.0 \pm 1.2^{*}$ & $60.2 \pm 6.7^{*}$ \\
T-030 & $6 \mu \mathrm{g}$ & 13 & 90.8 \\
T-030 & $9 \mu \mathrm{g}$ & 10 & 81.4 \\
\hline
\end{tabular}

Values \pm SD with * represent the mean of 3 independent experiments, each with 3 biological replicates. The other means are derived from one experiment with 3 biological replicates.

effective for primary cells, as our assessment of several widely used lipid reagents demonstrated, and alternate methods based on electroporation have been developed. Since its first report 25 years ago by Chu et al. [29], electroporation of mammalian cells has been modified and developed as a commercially available technology for use in studying difficult to transfect cell types. However, primary cells of different origins respond differently, and methods need to be carefully optimized for each cell type. We evaluated two electroporation-based technologies, the Neon transfection system based on methodological advances developed by Kim et al. [30] and the Amaxa Nucleofector II system based on methodology developed by Amaxa GmbH in 1998. Using the Neon transfection system with human primary cranial suture mesenchymal cells, at best we achieved a transfection efficiency of $10 \%$, much lower than other studies using this system with human stem cells from bone marrow, adipose tissue and umbilical cord blood, where transfection efficiencies of 35$80 \%$ have been reported [31-33]. In contrast, with the Amaxa Nucleofector II, transfection efficiencies of up to $90 \%$ were attained, although cell survival varied with the transfection kits and programs tested. With optimization of transfection program, transfection solution, amount of plasmid DNA and cell numbers, a protocol was developed that resulted in an average of $60 \%$ transfection efficiency with $20 \%$ cell survival. This transfection efficiency is comparable to that achieved in other primary cells and in stem cells using the Amaxa Nucleofector or other electroporators [34-39]. Although mortality of the human primary suture mesenchymal cells is higher compared to other cell types, sufficient numbers of transfected cells can be obtained for quantitative-based assays of gene and protein function, as demonstrated using the dual luciferase assay.

BMP2 is the best known bone osteogenic factor and induces osteoblastic differentiation of multipotent mesenchymal cells $[40,41]$. In contrast, BMP3, a less well known BMP, antagonizes BMP2 action by competing for binding to a common effector, SMAD4 [42,43]. Loss of BMP3 results in excessive bone formation $[42,43]$ and recent data show BMP3 suppresses osteoblastic differentiation and thereby is thought to limit the differentiation of osteoprogenitors [24]. Human primary suture cells have an osteoprogenitor-like phenotype and can be induced to differentiate with standard osteogenic supplements, ascorbic acid and $\beta$-glycerophosphate $[19,21]$. Cranial sutures express BMP2 [21,44] and BMP3 [45] and we used nucleofection of human primary suture cells to measure BMP2 and BMP3 signalling with luciferase reporter plasmids and demonstrate robust responses of the cells to both BMPs. It is possible that an interplay of these two BMPs may occur in vivo to influence in cranial bone growth, in which case that could provide an opportunity to manipulate and alter the outcome of abnormal bone growth in conditions such as craniosynostosis.

\section{Conclusions}

A nucleofection protocol has been developed that provides a simple and efficient, non-viral alternative method for in vitro studies of gene and protein function in human skull growth. Human primary suture mesenchymal cells exhibit robust responses to BMP2 and BMP3, and thus nucleofection can be a valuable method for studying the potential competing action of these two bone growth factors in a model system of cranial bone growth.

\section{Methods}

Human primary calvarial suture mesenchymal cells

Human primary calvarial suture mesenchymal cells, a heterogeneous population derived from the connective mesenchymal tissue between the bone forming regions at the edges of the calvarial plates of the skull, were grown from human suture samples as described previously [21] and were obtained from patients undergoing surgical treatment for craniosynostosis at the Australian

Table 4 Effect of increasing cells on cell survival and transfection efficiency using the cell line L kit and T030 program

\begin{tabular}{llllll}
\hline Program & Cells & pmaxGFP $(\boldsymbol{\mu g})$ & \% Cell survival & \% Transfection efficiency & \% Cell input, alive and transfected \\
\hline T-030 & 500,000 & No GFP control & $36.0 \pm 4.2^{*}$ & $0.4 \pm 0.2^{*}$ & 0.1 \\
T-030 & 500,000 & $3 \mu \mathrm{g}$ & $19.0 \pm 0.8^{*}$ & $61.3 \pm 5.5^{*}$ & 11.6 \\
T-030 & $1,000,000$ & $3 \mu \mathrm{g}$ & $13.0 \pm 1.0^{\#}$ & $88.5 \pm 2.3^{\#}$ & 11.5 \\
T-030 & $1,500,000$ & $3 \mu \mathrm{g}$ & $11.0 \pm 1.2^{\#}$ & $89.4 \pm 2.0^{\#}$ & 9.8 \\
\hline
\end{tabular}

Values \pm SD with * represent the mean of 4 independent experiments, each with 4 biological replicates and values with ${ }^{*}$ represent the mean of 2 independent experiments, each with 2 biological replicates. 

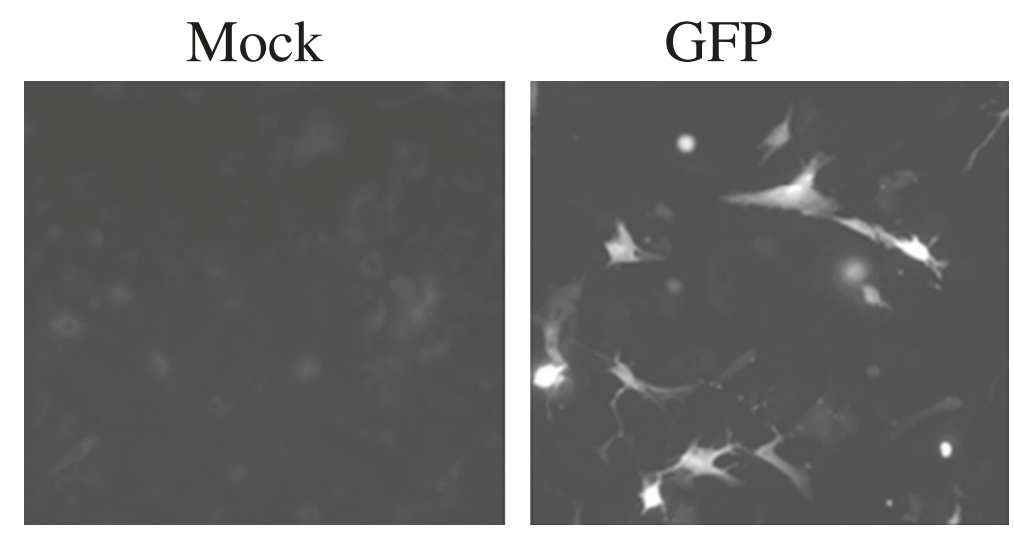

Figure 1 Microscopic analysis of nucleofected GFP in human primary calvarial suture mesenchymal cells. Human primary calvarial suture cells $\left(1.0 \times 10^{6}\right)$ were transfected with $3 \mu \mathrm{g}$ of pmaxGFP expression construct using Amaxa kit-L and the T030 program. The cells were imaged by light microscopy.

Craniofacial Unit of the Women's and Children's Hospital, Adelaide, South Australia. This work was approved by the Research Ethics Committee of the Women's and Children's Hospital (REC1033/10/2014) and was performed in compliance with the Helsinki Declaration for research involving human subjects. Written, informed consent was obtained from the child, parent or guardian according to the guidelines of the Research Ethics Committee of the Women's and Children's Hospital. Briefly, for experimental purposes, cells were grown in minimal medium (MM) consisting of high glucose Dulbecco's modified essential medium (DMEM, Invitrogen Life

\section{NTC Gpc3}

\section{0 bp $\rightarrow$}

\section{0 bp $\rightarrow$}

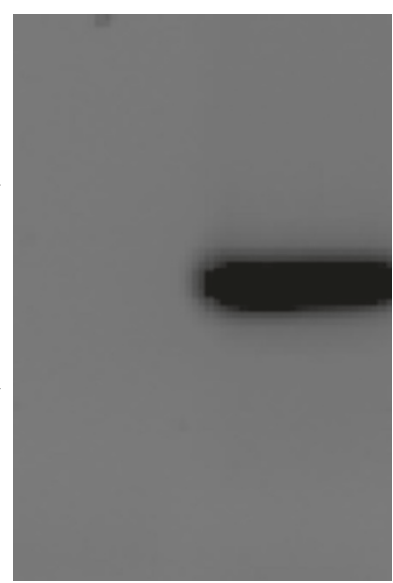

Figure 2 Expression of nucleofected Gpc3. Human primary calvarial suture cells $\left(1.0 \times 10^{6}\right)$ were transfected with $3 \mu \mathrm{g}$ of mouse Gpc3 expression construct using Amaxa kit-L and the T030 program. The amplified PCR product (174 bp) shows the expression of mouse Gpc3 while no template controls (NTC) shows no bands. The positions of 100 and 200 bp markers of a DNA ladder are indicated.
Technologies, Gaithersburg, MD), supplemented with LGlutamine ( $584 \mathrm{mg} / \mathrm{l}), 10 \%$ foetal bovine serum (Invitrogen, Carlsbad, CA, USA), $1 \%$ antibiotics (penicillin $100 \mathrm{IU} / \mathrm{ml})$, streptomycin $(100 \mu \mathrm{g} / \mathrm{ml})$ and $1 \%$ antibiotic:antimycotic (both purchased from Sigma-Aldrich, MI, USA) by incubating at $37^{\circ} \mathrm{C}$ in an humidified incubator with $5 \% \mathrm{CO}_{2}$ in air. The cultures comprise cells from the suture mesenchyme and adjacent bone growth fronts that exhibit a pre-osteoblastic or osteoprogenitor phenotype.

\section{Transfection of human primary calvarial suture} mesenchymal cells using various lipid-based methods In preparation for transfection using various lipid based methods, cells were grown in $175 \mathrm{~cm}^{2}$ flasks to $70-80 \%$ confluency. On the day of transfection, cells were washed once with PBS and trypsinized by adding $2 \mathrm{ml}$ of 1X trypsin (Sigma-Aldrich, St Louis, USA) and incubating the flask at $37^{\circ} \mathrm{C}$ for 2 mins. The cells were stained with trypan blue and counted using a haematocytometer. Transfections using DOTAP (N-[1-(2,3-Dioleoyloxypropyl] N,N,N -trimethyl ammonium methyl sulfate; Roche Applied Biosciences, Indianapolis, USA), Lipofectamine 2000 (Life Technologies, Invitrogen, Australia), Turbofect (Fermentas Inc., Maryland, USA), X-Fect (Clontech Laboratories Inc., CA, USA), Endofectine (GeneCopoeia Inc., MD, USA) and Metafectine (Biontex Laboratories, $\mathrm{GMbH}$, Germany) were carried out as described in manufacturer's supplied protocols and as previously described [46-48]. Briefly for transfection, human primary suture cells (50,000 cells / well) were seeded in a 24-well tray and grown in $400 \mu \mathrm{l}$ of minimal medium supplemented with $10 \%$ fetal bovine serum. The cells were attached by incubating at $37^{\circ} \mathrm{C}$ for $24 \mathrm{hrs}$. For each triplicate transfection, $750 \mathrm{ng}$ pmaxGFP (green fluorescent protein) expression construct (3.49 kb: Amaxa 

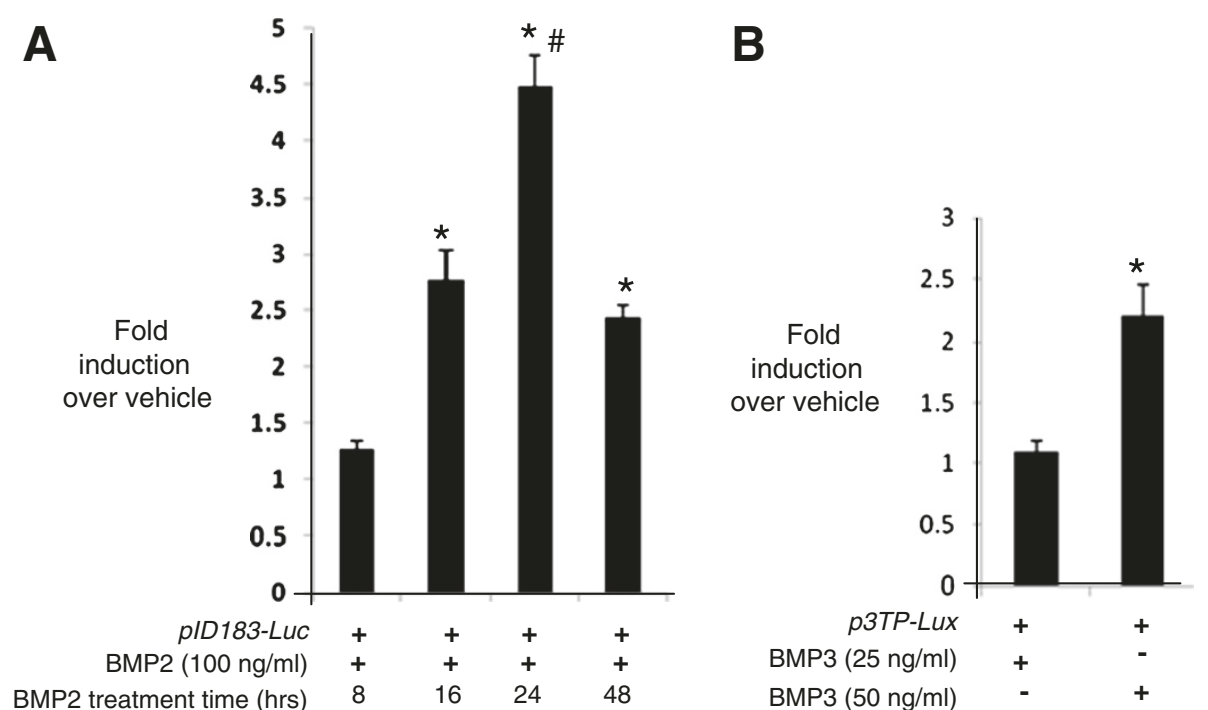

Figure 3 Functional analysis of nucleofected BMP2 and BMP3-responsive promoter reporters. Human primary calvarial suture cells (1.0 $x$ $10^{6}$ ) were nucleofected with $3 \mu \mathrm{g}$ of BMP2 responsive promoter construct (pID183-luc; 3A) or BMP3 responsive promoter construct ( $p 3 T$ TP-lux-Luc; 3B) using Amaxa kit-L and the T030 program. The cells were also co-nucleofected with pRL-TK-luc construct as an internal control for transfection efficiency. Each construct was incubated with BMP2 or BMP3 or vehicle as indicated in the figures. The fold induction shown is the ratio of luciferase activity from BMP2-treated or BMP3-treated to vehicle treatment (ie no BMP) at the appropriate time point. In Figure 3A, * shows responses that are significantly different to vehicle, and to BMP2 treatment at 8 hrs, and \# shows that 24 hrs BMP2 treatment is significantly different to all other time-points and treatments. In Figure $3 B$, * shows that the response to $50 \mathrm{ng} / \mathrm{ml}$ BMP3 is significantly different compared to vehicle and to the lower BMP3 dose. The data shows a representative result from three independent experiments, each performed with triplicate biological samples.

Biosystems, now known as Lonza) was mixed with $30 \mu \mathrm{l}$ of $20 \mathrm{mM}$ Hepes buffer $\mathrm{pH} 7.4$ in an eppendorf tube and, in another tube, the specific transfection agent was diluted with $30 \mu \mathrm{l}$ of Hepes buffer to the recommended concentrations. The contents of these tubes were mixed and incubated at room temperature for 20 mins for DNA-lipid complex formation and $20 \mu \mathrm{l}$ of this complex was aliquotted into three wells of a 24-well tissue culture tray. The next day the medium was removed and the cells washed once with $400 \mu \mathrm{l}$ of phosphate-buffered saline (PBS) and replaced with $400 \mu \mathrm{l}$ of medium, then incubated at $37^{\circ} \mathrm{C}$ for another $24 \mathrm{hrs}$. Microscopy of the GFP-transfected cells was carried out using a Nikon Eclipse TE2000U inverted microscope attached with twin CCD cameras and 20x objective. Cells were then counted as indicated in the appropriate figure legends in an haematocytometer after trypan blue staining to calculate cell survival. Flow cytometric analysis of GFPpositive cells was conducted to determine transfection efficiency.

\section{Flow cytometry}

The expression vector, pmaxGFP, was transfected or nucleofected into human primary calvarial suture mesenchymal cells. At $24 \mathrm{hrs}$ post transfection cells were washed twice with PBS and dislodged from the tissue culture plates with $1 \mathrm{X}$ trypsin. Cells were then centrifuged at $1300 \mathrm{rpm}$ for 10 mins and resuspended in $100 \mu \mathrm{l}$ of PBS. $10 \mu \mathrm{l}$ of these cells were used for trypan blue staining to calculate cell survival and $90 \mu \mathrm{l}$ of the cells were further diluted to $200 \mu \mathrm{l}$ in PBS for analysis of transfection efficiency by flow cytometry. GFP fluorescence was analyzed using a BD Bioscience FACS-AriaII. Dead cells were gated out using 7-Aminoactinomycin D (7-AAD) $(5 \mu \mathrm{g} / \mathrm{ml})$ staining. Data were analyzed using Flowjo Version 7 (Free Star Inc., USA).

\section{Nucleofection of human primary calvarial suture mesenchymal cells using Amaxa transfection kits}

Nucleofection of human primary calvarial suture mesenchymal cells was carried out using the Amaxa-II Nucleofector method and available transfection kits. No kit was specifically available for the human primary calvarial suture mesenchymal cells under investigation in this study; therefore the Amaxa Cell Line Optimization Nucleofector Kit was tested for nucleofection of human primary suture cells. Briefly, in preparation for nucleofection, suture cells were dislodged from the tissue culture flask by trypsin and counted in a haematocytometer after trypan blue staining. All centrifugations were carried out with maximum g force of $150 \mathrm{~g}$. For each nucleofection, suture cells were resuspended in $100 \mu \mathrm{l}$ of $\mathrm{V}$ or $\mathrm{L}$ Nucleofector solution and $20 \mu \mathrm{l}$ of the Amaxa Supplement in an eppendorf tube. The appropriate amount of 
pmaxGFP was also mixed as indicated in the respective tables and figure legends. Immediately, the mixture of suture cells, pmaxGFP and Nucleofector solution was transferred into an Amaxa cuvette and nucleofection conducted using the recommended program. The nucleofected cells were resuspended in $400 \mu \mathrm{l}$ of minimal media and plated into a 24-well tissue culture tray. The cells were incubated overnight at $37^{\circ} \mathrm{C}$. The next day the medium was removed and the cells were washed three times with $400 \mu \mathrm{l}$ of PBS and the medium replaced with serum-free DMEM and the cells incubated at $37^{\circ} \mathrm{C}$ for a further $24 \mathrm{hrs}$. The following day, microscopy of the GFP-transfected cells was carried out and then cells were trypsinized and resuspended in $100 \mu \mathrm{l}$ of PBS. Cells $(10 \mu \mathrm{l})$ were counted in a haematocytometer after trypan blue staining to calculate cell survival. The remaining cells were analysed for GFP expression by flow cytometry analysis and transfection efficiency was determined.

\section{Construction of Gpc3 expression vector}

A mouse ORF cDNA (1.74 kb) for glypican 3 (Gpc3) and the gateway cloning vector, pcDNA-DEST40 (7.1 kb) were purchased (GeneCopoeia Inc., MD, USA). Gateway cloning was carried out essentially as described in the manufacturer's protocol. The construct was verified using restriction digestion analysis and DNA sequence analysis (Applied Biosystems, CA, USA).

\section{Gene expression analysis of nucleofected Gpc3 by RT-PCR}

The Gpc3 expression construct $(8.84 \mathrm{~kb})$ was nucleofected using optimized transfection conditions (Amaxa transfection kit L and program T030) for human primary calvarial suture mesenchymal cells. Gpc3 nucleofected cells were grown in 24 well tissue culture tray for $24 \mathrm{hrs}$ then washed three times with PBS and grown overnight. RNA was extracted using an RNAeasy mini kit (Qiagen, CA, USA) and cDNA synthesized from 200 ng RNA using a Superscript-III First Strand Synthesis kit (Invitrogen, CA, USA). Primers for Gpc3 (forward 5'-ggttagccagatcattgacaaac-3' and reverse 5'-cttcatcatcac cgcagtctc-3') were synthesized (Geneworks, Adelaide, South Australia). The primers were specific for nucleofected mouse Gpc3. PCR reactions were carried out using $2 \mu \mathrm{l} \mathrm{cDNA}, 100 \mathrm{X}$ SYBR green (Abgene, Epson, UK), 1X Amplitaq PCR buffer, $2 \mathrm{mM} \mathrm{MgCl}_{2}, 1$ unit of Amplitaq (Applied Biosystems, Foster City, CA, USA), $0.4 \mathrm{mM}$ dNTPs (Invitrogen, Carlsbad, CA, USA) and $5.625 \mu \mathrm{M}$ primers in $25 \mu \mathrm{l}$. PCR was carried out using a Gene Amp PCR System 9700 (Applied Biosystems). An expected PCR product (174 bp) was resolved on a $1.5 \%$ agarose gel. The PCR product was sequenced for confirmation (Institute of Medical and Veterinary Sciences, Adelaide, Australia).

\section{Functional analysis of BMP2 and BMP3 using promoter- reporter assays}

For transient transfection analysis, human primary calvarial suture mesenchymal cells were grown in $175 \mathrm{~cm}^{2}$ flasks to 70-80 \% confluency. On the day of transfection cells were washed once with PBS and trypsinized by adding $2 \mathrm{ml}$ of $1 \mathrm{X}$ trypsin and incubating the flask in a $37^{\circ} \mathrm{C}$ incubator for 2 mins. The cells were stained with trypan blue and counted using a haematocytometer. Transfection was conducted using the Nucleofector kit $\mathrm{L}$ and program T030. In preparation for transfection, 1.5 x $10^{6}$ cells were resuspended in $100 \mu$ of Nucleofector transfection solution with $3 \mu \mathrm{g}$ of a BMP responsive promoter luciferase construct, pID183-Luc $(5.78 \mathrm{~kb})$ [25] or a TGF beta responsive promoter luciferase construct, p3TP-Lux (6.55 kb) [26] together with $500 \mathrm{ng}$ of pRLTKLuc construct (4.05 kb: Promega Corporation, USA) as a control to normalize transfection efficiency. The transfected cells were transferred to $3 \mathrm{ml}$ of pre-warmed medium and $200 \mu \mathrm{l}$ of cells were aliquotted to 96-well plates and incubated for $24 \mathrm{hrs}$ in a $37^{\circ} \mathrm{C}$ incubator with $5 \% \mathrm{CO}_{2}$. The following day cells were washed 3 times with PBS and then incubated with $200 \mu \mathrm{l}$ of serum-free DMEM with antibiotic and BMP2 and BMP3 (R\&D Systems, USA) as indicated in figure legends and cells were cultured for up to $48 \mathrm{hrs}$. Luciferase activity in cell lysates was determined using the Dual Luciferase Assay kit and a Luminometer as described previously $[48,49]$.

\section{Statistical analysis}

Results are presented as mean value of 2 to 4 biological replicates with standard deviation (SD) where appropriate. Specific assays were statistically analyzed using Analysis of Variance (ANOVA). The differences were considered significant when the $\mathrm{P}$ value was less than 0.05 .

\section{Abbreviations}

GFP: Green fluorescent protein; GPC3: Glypican 3; BMP: Bone morphogenetic protein; Luc: Luciferase.

\section{Competing interests}

The authors declare no competing interests.

\section{Authors' contributions}

PPD, PJA and BCP designed the study. PJA collected human tissue samples and established the primary cultures. PPD performed the experiments. All authors contributed to the manuscript and have read and approved the final manuscript.

\section{Authors' information}

PPD and BCP are molecular biologists. PJA is a craniofacial surgeon.

\section{Acknowledgements}

The authors thank Prof Francesc Ventura (Departament de Ciènceies Fisiològiques II, Universitat de Barcelona, Spain) for the pID183-LuC vector and Prof Nicholas Saunders (Center for Immunology and Cancer Research, University of Queensland, Brisbane, Australia) for the p3TP-Lux vector, Prof David David (Australian Craniofacial Unit, Women's and Children's Hospital, 
Adelaide, Australia) for providing some of the patient samples and Sylvia Nobbs (Discipline of Paediatrics, University of Adelaide, Australia) for help with flow cytometry. Genotyping of patients was carried out by Dr Michael Buckley (Seals Laboratory, Westmead Hospital, Sydney, Australia). This study was supported in part by the National Health \& Medical Research Council, the Channel 7 Children's Research Foundation, the Women's and Children's Research Foundation, the Australian CranioMaxilloFacial Foundation and the Harwood Foundation.

\section{Author details}

${ }^{1}$ Craniofacial Research Group, Women's and Children's Health Research Institute, 72 King William Road, North Adelaide, South Australia 5006, Australia. ${ }^{2}$ Discipline of Paediatrics, University of Adelaide, North Terrace Adelaide, South Australia 5006, Australia. ${ }^{3}$ Australian Craniofacial Unit, Women's and Children's Hospital, North Adelaide, South Australia 5006, Australia.

Received: 14 May 2012 Accepted: 25 July 2012

Published: 3 August 2012

\section{References}

1. Zhang X, Godbey WT: Viral vectors for gene delivery in tissue engineering. Adv Drug Deliv Rev 2006, 58:515-534.

2. Welm BE, Dijkgraaf GJ, Bledau AS, Welm AL, Werb Z: Lentiviral transduction of mammary stem cells for analysis of gene function during development and cancer. Cell Stem Cell 2008, 2:90-102.

3. Partridge KA, Oreffo RO: Gene delivery in bone tissue engineering: progress and prospects using viral and nonviral strategies. Tissue Eng 2004, 10:295-307.

4. Anson DS, Mclntyre C, Thomas B, Koldej R, Ranieri E, Roberts A, Clements PR, Dunning K, Byers S: Lentiviral-mediated gene correction of mucopolysaccharidosis type IIIA. Genet Vaccines Ther 2007, 5:1.

5. Hamm A, Krott N, Breibach I, Blindt R, Bosserhoff AK: Efficient transfection method for primary cells. Tissue Eng 2002, 8:235-245.

6. Tervo HM, Allespach I, Keppler OT: High-level transfection of primary rabbit T lymphocytes. J Immunol Methods 2008, 336:85-89.

7. Schnoor M, Buers I, Sietmann A, Brodde MF, Hofnagel O, Robenek H, Lorkowski S: Efficient non-viral transfection of THP-1 cells. J Immunol Methods 2009, 344:109-115.

8. Haag J, Voigt R, Soeder S, Aigner T: Efficient non-viral transfection of primary human adult chondrocytes in a high-throughput format. Osteoarthr Cartil 2009, 17:813-817.

9. Pedersen CD, Fang JJ, Pedersen AE: A comparative study of transfection methods for RNA interference in bone marrow-derived murine dendritic cells. Scand J Immunol 2009, 70:447-456.

10. Maurisse R, De Semir D, Emamekhoo H, Bedayat B, Abdolmohammadi A, Parsi H, Gruenert DC: Comparative transfection of DNA into primary and transformed mammalian cells from different lineages. BMC Biotechnol 2010, 10:9.

11. Mackie EJ, Ahmed YA, Tatarczuch L, Chen KS, Mirams M: Endochondral ossification: how cartilage is converted into bone in the developing skeleton. Int J Biochem Cell Biol 2008, 40:46-62.

12. Hojo H, Ohba S, Yano F, Chung Ul: Coordination of chondrogenesis and osteogenesis by hypertrophic chondrocytes in endochondral bone development. J Bone Miner Metab 2010, 28:489-502.

13. Karaplis AC: Embryonic Development of Bone and Regulation of Intramembranous and Endochondral Bone Formation. In Principles of Bone Biology. Thirdth edition. Edited by John PB, Lawrence GR, Martin TJ. San Diego: Academic Press; 2008:53-84.

14. Morriss-Kay GM, Wilkie AO: Growth of the normal skull vault and its alteration in craniosynostosis: insights from human genetics and experimental studies. J Anat 2005, 207:637-653.

15. Khong JJ, Anderson P, Gray TL, Hammerton M, Selva D, David D Ophthalmic findings in apert syndrome prior to craniofacial surgery. Am J Ophthalmol 2006, 142:328-330.

16. Gray TL, Casey T, Selva D, Anderson PJ, David DJ: Ophthalmic sequelae of Crouzon syndrome. Ophthalmology 2005, 112:1129-1134.

17. Wilkie AO, Oldridge M, Tang Z, Maxson RE Jr: Craniosynostosis and related limb anomalies. Novartis Found Symp 2001, 232:122-133. discussion 133-143.
18. Cunningham ML, Seto ML, Ratisoontorn C, Heike CL, Hing AV: Syndromic craniosynostosis: from history to hydrogen bonds. Orthod Craniofac Res 2007, 10:67-81.

19. Coussens AK, Hughes IP, Morris CP, Powell BC, Anderson PJ: In vitro differentiation of human suture cells with and without dexamethasone does not induce in vivo-like expression. J Cell Physiol 2009, 218:183-191.

20. Coussens AK, Wilkinson CR, Hughes IP, Morris CP, Daal A, Anderson PJ, Powell BC: Unravelling the molecular control of calvarial suture morphogenesis in children with craniosynostosis. BMC Genomics 2007 8:458.

21. Coussens AK, Wilkinson CR, Hughes IP, Powell BC, Anderson PJ, Daal A: Identification of genes differentially expressed by prematurely fused human sutures using a novel in vivo-in vitro approach. Differentiation 2008, 76:531-545.

22. Filmus J, Capurro M, Rast J: Glypicans. Genome Biol 2008, 9:224-230.

23. Rosen V: BMP and BMP inhibitors in bone. Ann N Y Acad Sci 2006, 1068:19-25.

24. Kokabu S, Gamer L, Cox K, Lowery J, Tsuji K, Raz R, Economides A, Katagiri T, Rosen V: BMP3 suppresses osteoblast differentiation of bone marrow stromal cells via interaction with Acvr2b. Mol Endocrinol 2012, 26:87-94.

25. Lopez-Rovira T, Chalaux E, Massague J, Rosa JL, Ventura F: Direct binding of Smad1 and Smad4 to two distinct motifs mediates bone morphogenetic protein-specific transcriptional activation of Id1 gene. J Biol Chem 2002, 277:3176-3185.

26. Wrana JL, Attisano L, Carcamo J, Zentella A, Doody J, Laiho M, Wang XF, Massague J: TGF beta signals through a heteromeric protein kinase receptor complex. Cell 1992, 71:1003-1014.

27. Guenou H, Kaabeche K, Dufour C, Miraoui H, Marie PJ: Down-regulation of ubiquitin ligase $\mathrm{Cbl}$ induced by twist haploinsufficiency in SaethreChotzen syndrome results in increased PI3K/Akt signaling and osteoblast proliferation. Am J Pathol 2006, 169:1303-1311.

28. Guenou H, Kaabeche K, Mee SL, Marie PJ: A role for fibroblast growth factor receptor- 2 in the altered osteoblast phenotype induced by Twist haploinsufficiency in the Saethre-Chotzen syndrome. Hum Mol Genet 2005, 14:1429-1439.

29. Chu G, Hayakawa H, Berg P: Electroporation for the efficient transfection of mammalian cells with DNA. Nucleic Acids Res 1987, 15:1311-1326.

30. Kim JA, Cho K, Shin MS, Lee WG, Jung N, Chung C, Chang JK: A novel electroporation method using a capillary and wire-type electrode. Biosens Bioelectron 2008, 23:1353-1360.

31. Madeira C, Ribeiro SC, Pinheiro IS, Martins SA, Andrade PZ, da Silva CL, Cabral JM: Gene delivery to human bone marrow mesenchymal stem cells by microporation. J Biotechnol 2011, 151:130-136.

32. Wang $\mathrm{YH}, \mathrm{Ho} \mathrm{ML}$, Chang JK, Chu HC, Lai SC, Wang GJ: Microporation is a valuable transfection method for gene expression in human adipose tissue-derived stem cells. Mol Ther 2009, 17:302-308.

33. Lim JY, Park SH, Jeong CH, Oh JH, Kim SM, Ryu CH, Park SA, Ahn JG, Oh W, Jeun SS, Chang JW: Microporation is a valuable transfection method for efficient gene delivery into human umbilical cord blood-derived mesenchymal stem cells. BMC Biotechnol 2010, 10:38.

34. Gresch O, Engel FB, Nesic D, Tran TT, England HM, Hickman ES, Korner I, Gan L, Chen S, Castro-Obregon S, et al: New non-viral method for gene transfer into primary cells. Methods 2004, 33:151-163.

35. Nakayama A, Sato M, Shinohara M, Matsubara S, Yokomine T, Akasaka E, Yoshida M, Takao S: Efficient transfection of primarily cultured porcine embryonic fibroblasts using the Amaxa Nucleofection system. Cloning Stem Cells 2007, 9:523-534.

36. Aluigi M, Fogli M, Curti A, Isidori A, Gruppioni E, Chiodoni C, Colombo MP, Versura P, D'Errico-Grigioni A, Ferri E, et al: Nucleofection is an efficient nonviral transfection technique for human bone marrow-derived mesenchymal stem cells. Stem Cells 2006, 24:454-461.

37. Aslan H, Zilberman Y, Arbeli V, Sheyn D, Matan Y, Liebergall M, Li JZ, Helm GA, Gazit D, Gazit Z: Nucleofection-based ex vivo nonviral gene delivery to human stem cells as a platform for tissue regeneration. Tissue Eng 2006, 12:877-889.

38. Ferreira E, Potier E, Logeart-Avramoglou D, Salomskaite-Davalgiene S, Mir LM, Petite H: Optimization of a gene electrotransfer method for mesenchymal stem cell transfection. Gene Ther 2008, 15:537-544.

39. Helledie T, Nurcombe V, Cool SM: A simple and reliable electroporation method for human bone marrow mesenchymal stem cells. Stem Cells Dev 2008, 17:837-848. 
40. Vaes BL, Dechering KJ, Feijen A, Hendriks JM, Lefevre C, Mummery CL, Olijve W, van Zoelen EJ, Steegenga WT: Comprehensive microarray analysis of bone morphogenetic protein 2-induced osteoblast differentiation resulting in the identification of novel markers for bone development. J Bone Miner Res 2002, 17:2106-2118.

41. Yamaguchi A, Komori T, Suda T: Regulation of osteoblast differentiation mediated by bone morphogenetic proteins, hedgehogs, and Cbfa1. Endocr Rev 2000, 21:393-411.

42. Daluiski A, Engstrand T, Bahamonde ME, Gamer LW, Agius E, Stevenson SL, Cox K, Rosen V, Lyons KM: Bone morphogenetic protein-3 is a negative regulator of bone density. Nat Genet 2001, 27:84-88.

43. Bahamonde ME, Lyons KM: BMP3: to be or not to be a BMP. J Bone Joint Surg Am 2001, 83-A(Suppl 1):S56-62.

44. Kim HJ, Rice DP, Kettunen PJ, Thesleff I: FGF-, BMP- and Shh-mediated signalling pathways in the regulation of cranial suture morphogenesis and calvarial bone development. Development 1998, 125:1241-1251.

45. Nacamuli RP, Fong KD, Lenton KA, Song HM, Fang TD, Salim A, Longaker MT: Expression and possible mechanisms of regulation of BMP3 in rat cranial sutures. Plast Reconstr Surg 2005, 116:1353-1362.

46. Dwivedi PP, Anderson PH, Omdahl JL, Grimes HL, Morris HA, May BK: Identification of growth factor independent-1 (GFI1) as a repressor of 25-hydroxyvitamin D 1-alpha hydroxylase (CYP27B1) gene expression in human prostate cancer cells. Endocr Relat Cancer 2005, 12:351-365.

47. Dwivedi PP, Gao XH, Tan JC, Evdokiou A, Ferrante A, Morris HA, May BK, Hii CS: A role for the phosphatidylinositol 3-kinase-protein kinase $C$ zeta-Sp1 pathway in the 1,25-dihydroxyvitamin D3 induction of the 25hydroxyvitamin D3 24-hydroxylase gene in human kidney cells. Cell Signalling 2010, 22:543-552.

48. Dwivedi PP, Hii CS, Ferrante A, Tan J, Der CJ, Omdahl JL, Morris HA, May BK: Role of MAP kinases in the 1,25-dihydroxyvitamin D3-induced transactivation of the rat cytochrome P450C24 (CYP24) promoter. Specific functions for ERK1/ERK2 and ERK5. J Biol Chem 2002, 277:29643-29653.

49. Dwivedi PP, Omdahl JL, Kola I, Hume DA, May BK: Regulation of rat cytochrome P450C24 (CYP24) gene expression. Evidence for functional cooperation of Ras-activated Ets transcription factors with the vitamin D receptor in 1,25-dihydroxyvitamin $\mathrm{D}(3)$-mediated induction. $J \mathrm{Bio} / \mathrm{Chem}$ 2000, 275:47-55

doi:10.1186/1472-6750-12-45

Cite this article as: Dwivedi et al:: Development of an efficient, non-viral transfection method for studying gene function and bone growth in human primary cranial suture mesenchymal cells reveals that the cells respond to BMP2 and BMP3. BMC Biotechnology 2012 12:45.

\section{Submit your next manuscript to BioMed Central and take full advantage of:}

- Convenient online submission

- Thorough peer review

- No space constraints or color figure charges

- Immediate publication on acceptance

- Inclusion in PubMed, CAS, Scopus and Google Scholar

- Research which is freely available for redistribution 